\title{
Effect of Music on Blood Pressure and Heart Rate in Patients Undergoing Cataract Extraction Surgery
}

\author{
Aditi Gadegone ${ }^{1}$, Sachin Daigavane ${ }^{2}$, Ruta Walavalkar ${ }^{3}$ \\ ${ }^{1,2,3}$ Department of Ophthalmology, Jawaharlal Nehru Medical College, Datta Meghe Institute of Medical \\ Sciences (Deemed to Be University) Sawangi, Meghe, Wardha, Maharashtra, India.
}

\section{ABSTRACT}

\section{BACKGROUND}

Music is an inexpensive, easily available anxiolytic known to mankind since ages. Cataract extraction surgery is one of the widely performed surgeries under local anaesthesia. India is a developing country where limited resources are spent over health infrastructure which has to cater to a large population. In our study we have tried to utilize the anxietolytic effect of music in combating the anxiety and stress patients suffer during surgery.

\section{METHODS}

In this prospective, interventional study, 300 patients diagnosed with senile cataract were selected. The sample size was decided taking into consideration various prevalence studies. The patients were consequently recruited for the study considering the inclusion and exclusion criteria. Patients were divided into three groups - one undergoing phacoemulsification surgery under topical anaesthesia and two groups undergoing phacoemulsification surgery under local anaesthesia by the same surgeon in a same operating room. Two groups including the one where topical anaesthesia was used were made to listen to 'Classical Sitar Music' whereas one group was not made to listen to music. Blood pressure and heart rates were measured before and after surgery and compared in all patients.

\section{RESULTS}

Blood pressure and heart rates were statistically significantly normalized (lowered) post-operatively when compared to their pre-operative values in groups which were made to listen to music. There was a marked decrease in the anxiety levels in patients who were operated under topical anaesthesia when compared to those operated under local anaesthesia.

\section{CONCLUSIONS}

Music can be widely used in decreasing anxiety levels in patients undergoing cataract extraction surgery thereby improving the post-operative prognosis in patients in a cost-effective way.

\section{KEY WORDS}

Phacoemulsification Surgery, Classical Sitar Music, Peri-Bulbar Block, Topical Anaesthesia, Anxiety, Blood Pressure, Pulse Rate
Corresponding Author: Dr. Ruta Walavalkar, F-9, Radhikabai P.G. girl's hostel, JNMC Campus, Sawangi, Meghe, Wardha, Maharashtra, India. E-mail: rutawalavalkar@gmail.com

DOI: $10.14260 / j e m d s / 2021 / 309$

How to Cite This Article:

Gadegone A, Daigavane S, Walavalkar R. Effect of music on blood pressure and heart rate in patients undergoing cataract extraction surgery. J Evolution Med Dent Sci 2021;10(20):1474-1478, $10.14260 /$ jemds/2021/309

Submission 27-12-2020,

Peer Review 11-03-2021,

Acceptance 19-03-2021,

Published 17-05-2021.

Copyright (c) 2021 JEMDS. This is an open access article distributed under Creative Commons Attribution License [Attribution 4.0 International (CC BY 4.0)] 


\section{BACKGROUND}

Cataract extraction surgery has seen a revolutionary change in the past century. The latest technique of cataract extraction is better than the previous in all aspects including having much lesser post-operative complications. ${ }^{1}$ The goal of every surgeon is to prevent complications and provide comfort to the patient as much as possible. Development has also been seen in the type of anaesthesia used. Local peribulbar, retrobulbar and subconjunctival anaesthesia have been replaced by topical anaesthesia by many surgeons. ${ }^{2}$

Having said so, the innate nature of performing cataract surgery under local or topical anaesthesia where the patient is fully aware of his surroundings during surgery can prove to be bane especially for the older population when the eye surgeon deals with. Even minor surgical procedures can produce anxiety in anticipation of events that will be unfamiliar, uncomfortable, or have undesirable results in patients. ${ }^{3}$ The physical and measurable manifestation of anxiety is raised heart rate and blood pressure. This can affect their postoperative recovery and increase risk for physiological complications. Music is an easily administered, nonthreatening, non-invasive and inexpensive tool to calm preoperative anxiety. Music has proven over the years to provide comfort from a discomforting condition; familiarity in a strange environment and distraction from fear, pain and anxiety. 4,5

We wanted to find out if the utilization of the abovementioned properties of music is effective in reducing the anxiety and fear among patients undergoing cataract extraction.

\section{METHODS}

The study was approved by the institutional ethics committee of Datta Meghe Institute of Medical Sciences (Deemed to Be University), Sawangi, Wardha and adheres to the tenets of Declaration of Helsinki.

\section{Sample Size}

Sample size formula for difference between two means

$$
\mathrm{n}=\left(\mathrm{Z}_{\propto / 2}+\mathrm{Z}_{\beta}\right)^{2 *} 2^{*} \sigma^{2} / \mathrm{d}^{2}
$$

where $\mathrm{Z}_{\propto / 2}$ is the critical value of the normal distribution at $\alpha / 2$ (e.g., for a confidence level of $95 \%, \alpha$ is 0.05 and the critical value is 1.96), $Z_{\beta}$ is the critical value of the normal distribution at $\beta$ (e.g., for a power of $80 \%, \beta$ is 0.2 and the critical value is 0.84 ), $\sigma^{2}$ is the population variance, and $d$ is the difference you would like to detect.

$\mathrm{n}=(1.96+0.84)^{\wedge} 2 \times\left(9.5^{\wedge} 2+8.7^{\wedge} 2 / 1\right) / 3.3^{\wedge} 2$

$=119.46$

$\mathrm{N}=120$ patients needed in each group 100 patients were included and studied in each of the three groups.

\section{Data Collection Tools and Process}

In this prospective, interventional study, 300 patients diagnosed with senile cataract were enrolled. Patients falling in the age group of 40 - 80 years were included. The study was conducted in a duration of six months from May 2020 to October 2020. Patients with diabetes mellitus, uncontrolled hypertension and other co-morbid conditions such as chronic renal failure, history of stroke, recent myocardial infarction, psychiatric (not psychological) condition in the patient and deaf patients were excluded from the study, along with patients not giving consent.

Patients were divided into three groups, the music intervention group under topical anaesthesia (TMI) - Group A, the music intervention group under local anaesthesia (Group B) and the control group - Group C (no music).

Group A patients underwent phacoemulsification surgery under topical anaesthesia (2 - 3 drops of eyedrop $0.5 \%$ Proparacaine) and Group B and C patients underwent phacoemulsification surgery under local anaesthesia (peribulbar block with $6 \mathrm{ml}$ xylocaine $2 \%+$ bupivacaine 0.75 $\%+75$ units of hyaluronidase without adrenaline ) by a single experienced surgeon in the same surgical setting. Group A and B were made to listen to 'Classical Sitar Music' during the surgery by earphones. Whereas group $\mathrm{C}$ patients were not subjected to the music.

Pre-operatively, blood pressure was measured using a single sphygmomanometer about half an hour before surgery along with heart rate which was measured manually by a single post-graduate student in all patients to avoid bias. The same student then measured blood pressure by the same instrument and heart rates manually in all patients immediately after surgery. Pre-operative blood pressure and heart rates were then compared with post-operative values in all the three groups.

\section{Statistical Analysis}

Statistical analysis was done by using descriptive and inferential statistics using Student's paired t test and one-way analysis of variance (ANOVA) and software used in the analysis was SPSS 24.0 version and $\mathrm{P}<0.05$ was considered as level of significance.

\section{RESULTS}

A total of 300 patients were evaluated. Patients were divided into 3 groups namely Group A where phacoemulsification with topical anaesthesia was done. Group B where phacoemulsification was done under peribulbar anaesthesia. Group C where phacoemulsification under peribulbar anaesthesia.

Group A and B patients were made to listen to music whereas Group $C$ patients were not made to listen to music. The mean age in group A was 67.63 years in group B was 68.26 and group C was 66.64 years. Gender ratio mal : female is 50 : 50 in all three groups.

Pre-operative mean systolic blood pressure in group A was $140.87 \pm 11.66$, in group B was $137.61 \pm 11.38$ and in group $C$ was $135.34 \pm 11.03$. Post-operatively in group $\mathrm{A}$, the mean 
systolic blood pressure fell significantly to $122.36 \pm 8.16$ in group B it fell to $129.90 \pm 9.37$ whereas the mean systolic blood pressure significantly increased to $140.88 \pm 9.26$ in group C. It was observed that the systolic blood pressure decreased more in group A than in group B.

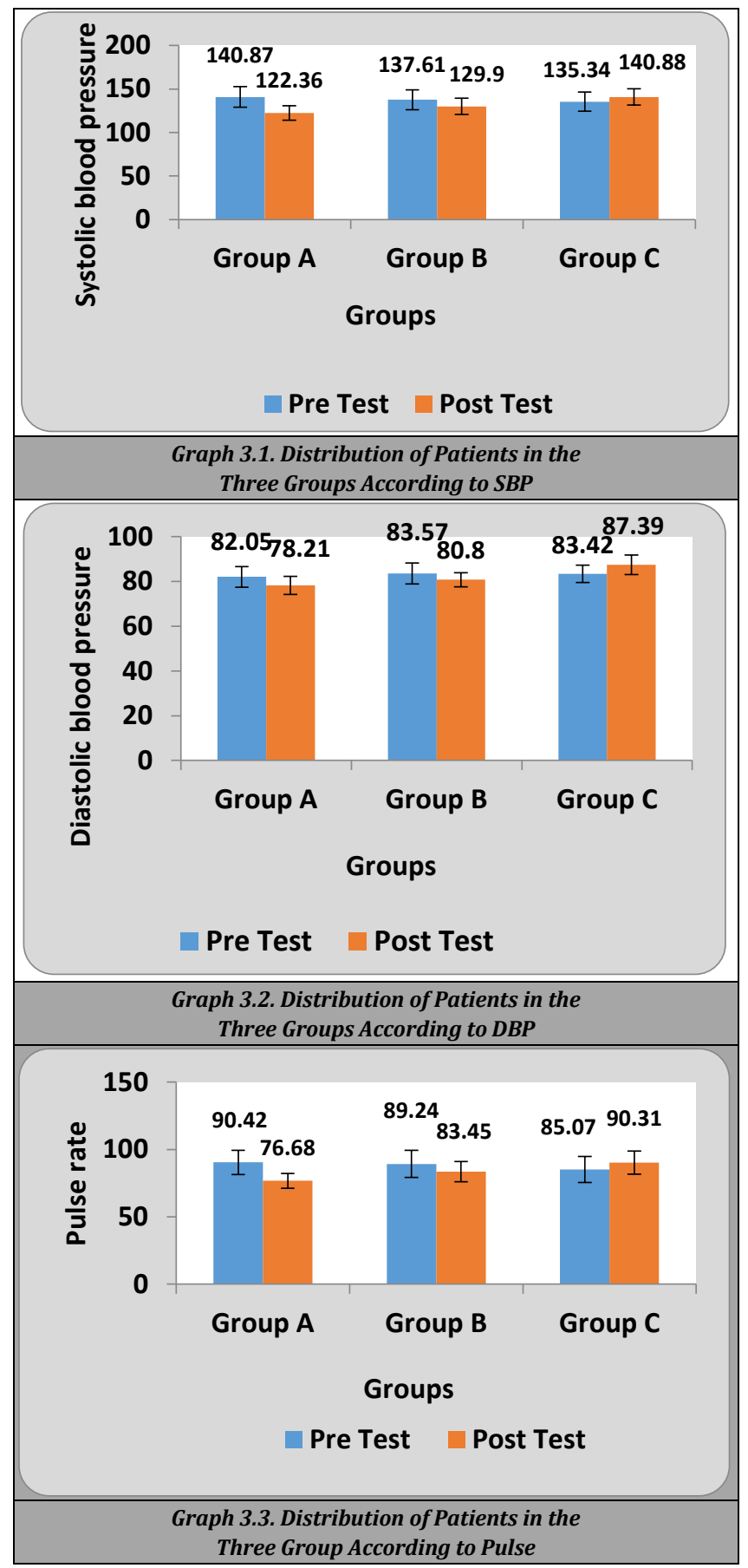

\begin{tabular}{|ccccccc|}
\hline Group & N & Mean & $\begin{array}{c}\text { Std. } \\
\text { Deviation }\end{array}$ & $\begin{array}{c}\text { Std. } \\
\text { Error }\end{array}$ & Minimum Maximum \\
\hline Group A & 100 & 67.63 & 11.29 & 1.12 & 42.00 & 88.00 \\
Group B & 100 & 68.26 & 10.43 & 1.04 & 46.00 & 85.00 \\
Group C & 100 & 66.64 & 11.05 & 1.10 & 40.00 & 88.00 \\
\hline \multicolumn{7}{c}{ Table 1. Mean Age in the Three Groups } \\
\hline
\end{tabular}

\begin{tabular}{|ccccc|}
\hline Gender & Group A & Group B & Group C & Total \\
& 50 & 50 & 50 & $\mathbf{1 5 0}$ \\
Male & 50 & 50 & 50 & 150 \\
Female & 100 & 100 & 100 & $\mathbf{3 0}$ \\
\hline Total & Table 2. Gender Wise Distribution of Patients in the Three Groups \\
\hline
\end{tabular}

\begin{tabular}{|c|c|c|c|c|c|}
\hline & & Group A & Group B & Group C & F - Value \\
\hline \multirow{3}{*}{ SBP } & Pre-Test & $140.87 \pm 11.66$ & $137.61 \pm 11.38$ & $135.34 \pm 11.03$ & $\begin{array}{c}5.98 \\
\mathrm{P}=0.003 \mathrm{~S}\end{array}$ \\
\hline & Post Test & $122.36 \pm 8.16$ & $129.90 \pm 9.37$ & $140.88 \pm 9.26$ & $\begin{array}{c}108.23 \\
\mathrm{P}=0.0001 \mathrm{~S}\end{array}$ \\
\hline & t-Value & $\begin{array}{c}22.85 \\
P=0.0001 \mathrm{~S}\end{array}$ & $\begin{array}{c}12.42 \\
P=0.0001 S\end{array}$ & $\begin{array}{c}11.56 \\
P=0.0001 S\end{array}$ & \\
\hline \multirow{3}{*}{ DBP } & Pre-Test & $82.05 \pm 4.60$ & $83.57 \pm 4.75$ & $83.42 \pm 3.83$ & $\begin{array}{c}3.59 \\
P=0.029 \mathrm{~S}\end{array}$ \\
\hline & Post Test & $78.21 \pm 4.08$ & $80.80 \pm 3.16$ & $87.39 \pm 4.34$ & $\begin{array}{c}147.31 \\
P=0.0001 S\end{array}$ \\
\hline & $\mathrm{t}$-Value & $\begin{array}{c}7.87 \\
\mathrm{P}=0.0001 \mathrm{~S}\end{array}$ & $\begin{array}{c}7.20 \\
\mathrm{P}=0.0001 \mathrm{~S}\end{array}$ & $\begin{array}{c}10.26 \\
P=0.0001 S\end{array}$ & \\
\hline \multirow{3}{*}{ Pulse } & Pre-Test & $90.42 \pm 9.01$ & $89.24 \pm 10.12$ & $85.07 \pm 9.65$ & $\begin{aligned} & 8.55 \\
\mathrm{P}= & 0.0001 \mathrm{~S}\end{aligned}$ \\
\hline & Post Test & $76.68 \pm 5.55$ & $83.45 \pm 7.56$ & $90.31 \pm 8.54$ & $\begin{array}{c}86.50 \\
P=0.0001 S\end{array}$ \\
\hline & $\mathrm{t}$-Value & $\begin{aligned} & 19.41 \\
P= & 0.0001, S\end{aligned}$ & $\begin{array}{c}7.8712 .63 \\
P=0.0001 S\end{array}$ & $\begin{array}{c}13.93 \\
P=0.0001 \mathrm{~S}\end{array}$ & \\
\hline & & ssment of $C l$ & cal Parame & s in the Thr & Groups \\
\hline
\end{tabular}

Pre-operative mean diastolic blood pressure in group A was $82.05 \pm 4.60$, in group $B$ was $83.57 \pm 4.75$ and in group $C$ was $83.42 \pm 3.83$. Post-operatively in group $\mathrm{A}$, the mean diastolic blood pressure fell significantly to $78.21 \pm 4.08$, in group B it fell to $80.80 \pm 3.16$ whereas the mean diastolic blood pressure significantly increased to $87.39 \pm 4.34$ in group C. It was observed that the diastolic blood pressure decreased more in group A than in group B.

Pre-operative mean pulse rate in group A was $90.42 \pm 9.01$, in group $B$ was $89.24 \pm 10.12$ and in group $C$ was $85.07 \pm 9.65$. Post - operatively in group A the pulse rate fell significantly to $76.68 \pm 5.55$ in group B it fell to $83.45 \pm 7.56$ whereas the mean pulse rate significantly increased to $90.31 \pm 8.54$ in group C. It was observed that the mean pulse rate decreased more in group A than in group B.

\section{DISCUSSION}

Music as we know is a natural healer of apprehension and has a trait of calming the person innately. This property of music to essentially soothe a person's mind can be used in treating pathological fear among patients undergoing surgery. Cataract extraction is an age-old surgical technique dating back to the $5^{\text {th }}$ century BC which used "couching" as a method to extract the cataractous lens.6,7

The amount of research done in the field of cataract is tremendous. The simple intracapsular cataract extraction where the whole capsular bag was removed in the $18^{\text {th }}$ century was replaced by extracapsular cataract extraction with placement of an artificial intraocular lens in the capsular bag. This technique improved the visual prognosis significantly.7,8

Research has been made in not only the technique of cataract extraction but also in the type of anaesthesia used. The peribulbar anaesthesia block which has been the standard form of anaesthesia has been replaced in many centres' worldwide with a shorter topical anaesthesia. This was possible due to the shorter time required with minimum surgical invasion done in the newer techniques of cataract extraction. Phacoemulsification with intra-ocular lens implantation under peribulbar anaesthesia as well as topical anaesthesia is the most popular surgical technique used world-wide and thus has been studied in this study as well. 
Cataract extraction surgery has thus been fashioned in such a way so as to provide minimum morbidity to the patient not only locally but also systemically.9,10 Although in practicality, clinicians face a number of hurdles in achieving zero post-operative and intra-operative complications. The prime and unavoidable reason would be the older population of patients the eye surgeon deals with. ${ }^{11,12}$ The average age in our study was 65 to 70 years of age too. Thus, in this age group patients are more prone to ill health and lesser compliance to a stressful condition such as surgery. Another factor in increased stress during cataract extraction surgery would be the fact that owing to the type of anaesthesia used in majority patients. The patients are aware of the surroundings in the operation theatre. The beeping of the pulse oximeter, the operation related talks among surgeons, the sound of instruments, the smell of anti-sceptics, etc that is sensed by the patient during surgery can provoke a sense of fear and anxiety in them. The intra-operative anxiety manifests as raised blood pressure and heart rate in such individuals leading to complications in the eye surgery. This effectively hampers the visual as well as systemic prognosis of the patient.

As music can mask the auditory stimulations in the operating room, it can be taken to our advantage in the patients who tend to get anxious due to the stressful surroundings. In our study, we studied 300 patients, out of which $50 \%$ were females and $50 \%$ males.

200 patients out of the 300 patients underwent phacoemulsification surgery under local anaesthesia while 100 patients underwent phacoemulsification surgery under topical anaesthesia by the same surgeon.

All 300 patients were divided in 3 groups each having 100 patients. First group (A) underwent phacoemulsification under topical anaesthesia and was made to listen to music during surgery. Second group (B) was made to listen to music while undergoing phacoemulsification under peribulbar anaesthesia. While the third group (C) was not made to listen to music while undergoing phacoemulsification surgery under peribulbar anaesthesia.

Blood pressure and heart rates of all patients were measured before and after surgery. The results indicated a statistically significant stabilization of blood pressure both systolic and diastolic along with heart rates in patients who were made to listen to soothing music in the operating room. The results also proved that the patients undergoing surgery under topical anaesthesia showed better results in terms of normalizing the blood pressure and heart rate.

This study thus has proved that the peribulbar block that is given before the surgery in majority of the cases can prove to be anxiety inducing as compared to the quicker topical anaesthetic drops instilled in the patient's eye. The reason for this finding could be the fear and apprehension of some patients towards the needle used for giving the block. The peribulbar block in itself leads to a number of complications such as retrobulbar haemorrhage, chemosis etc which might have lengthened the time of surgery, thus increasing the anxiety of patients.

\section{CONCLUSIONS}

Music has anxiolytic effect in patients undergoing cataract surgery. There was a statistically significant stabilization of vitals in patients undergoing surgery while listening to music. These findings add to the many studies on the benefits of music during surgery and our findings could potentially form part of the foundation for the development of specific interventions for pre-operative stress management. Health professionals may be educated appropriately in order to address stress reduction through music for their patients and train them accordingly. This result will thus prove to be a revolutionary change in the prognosis of post-operative patients, especially in developing countries where the medical resources are limited.

\section{Limitations}

Our study had a number of limitations too. The major limitation was that no cortisol and serological tests were applied to patients. These tests are the most reliable indicators of stress measurement. Another limitation was the generalizability of our findings, which is limited by the relatively small sample size. Additionally, the selected piece of music was determined by the researchers but not by the patients themselves. Of course, there may be other salient factors that may influence stress and may not have been considered in this study.

Data sharing statement provided by the authors is available with the full text of this article at jemds.com.

Financial or other competing interests: None.

Disclosure forms provided by the authors are available with the full text of this article at jemds.com.

\section{REFERENCES}

[1] Shah R. Anesthesia for cataract surgery: recent trends. Oman J Ophthalmol 2010;3(3):107-8.

[2] Waheeb S. Topical anesthesia in phacoemulsification. Oman J Ophthalmol 2010;3(3):136-9.

[3] Cruise CJ, Chung F, Yogendran S, et al. Music increases satisfaction in elderly outpatients undergoing cataract surgery. Can J Anaesth 1997;44(1):43-8.

[4] Mok E, Wong KY. Effects of music on patient anxiety. AORN J 2003;77(2):396-7.

[5] Thoma MV, La Marca R, Brönnimann R, et al. The effect of music on the human stress response. PLoS One 2013;8(8):e70156.

[6] Jawaharani A, Acharya S, Kumar S, et al. The effect of music therapy in critically ill patients admitted to the intensive care unit of a tertiary care center. J Datta Meghe Inst Med Sci Univ 2019;14(4):320-5.

[7] Gaberson KB. The effect of humorous distraction on preoperative anxiety. A pilot study. AORN J 1991;54(6):1258-64.

[8] Hoffman J. Tuning in to the power of music. RN 1997;60(6):52-4.

[9] Panjwani V, Daigavane S. A comparative study of corneal endothelial cell count and central corneal thickness in emmetropia and axial myopia. J Evolution Med Dent Sci 2020;9(44):3300-4.

[10] Chanchlani M, Sarkar N, Manghani J, et al. Evaluation of visual outcome after cataract surgery in camp patients- a 
study from Central India. Journal of Evolution of Medical and Dental Sciences 2014;3(6):1536-41.

[11] Desai S, Rao V. Visual outcome after cataract surgery in complicated cataract. Journal of Evolution of Medical and Dental Sciences 2014;3(34):9142-56.
[12] Chowdary CC, Sunanda V, Reddy YJ. Study of changes in serum electrolytes and its risk in development of senile cortical cataract. J Evolution Med Dent Sci 2018;7(27):3115-8. 